Article

\title{
Cross-Linking of Fibrex Gel by Fungal Laccase: Gel Rheological and Structural Characteristics
}

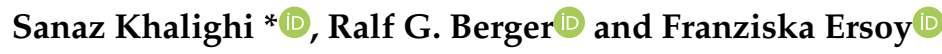 \\ Institute of food chemistry, Leibniz University Hannover, Callinstr. 5, 30167 Hannover, Germany; \\ rg.berger@lci.uni-hannover.de (R.G.B.); franziska.ersoy@lci.uni-hannover.de (F.E.) \\ * Correspondence: sanaz.khalighi@lci.uni-hannover.de; Tel.: +49-511-762-17257
}

Received: 26 November 2019; Accepted: 17 December 2019; Published: 20 December 2019

check for updates

\begin{abstract}
Sugar beet fibre (fibrex) is an abundant side-stream from the sugar refining industry.

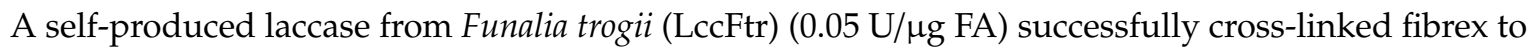
an edible gel. Dynamic oscillation measurements of the $10 \%$ fibrex gels showed a storage modulus of $5.52 \mathrm{kPa}$ and loss factors $\leq 0.36$ in the range from 20 to $80 \mathrm{~Hz}$. Comparing storage stability of sweetened $10 \%$ fibrex gels with sweetened commercial $6 \%$ gelatin gels (10\% and 30\% D-sucrose) indicated a constant storage modulus and loss factors $\leq 0.7$ during four weeks of storage in fibrex gels. Loss factors of sweetened gelatin gels were $\leq 0.2$, and their storage modulus decreased from 9 to $7 \mathrm{kPa}$ after adding D-sucrose and remained steady for four weeks of storage. Fibrex gel characteristics, including high water holding capacity, swelling ratio in saliva, and heat resistance are attributed to a covalently cross-linked network. Vanillin, as a mediator, and citrus pectin did not enhance covalent cross-links and elastic properties of the fibrex gels. Thus, laccase as an oxidative agent provided gels with a solid and stable texture. Fibrex gels may find uses in pharmaceutical and other industrial applications, which require a heat-resistant gel that forms easily at room temperature. They also represent an ethical alternative for manufacturing vegan, halal, and kosher food.
\end{abstract}

Keywords: fibrex gel; laccase; cross-linking; rheology; viscoelastic properties

\section{Introduction}

Fibrex is a dietary fibre, which represents an abundant side-stream from the sugar refining industry (approximately $200 \mathrm{~kg}$ of beet pulp per ton of sugar beet root) [1,2]. The main fibre types in fibrex are soluble pectin and insoluble hemi cellulose, but also small amounts of cellulose and lignin [3]. Sugar beet pectin contains arabinan $(\alpha-(1,5)$-linked L-arabinofuranosyl residues), and/or galactan $(\beta-(1$, 4)-linked $D$-galactose residues) as side chains of the rhamnogalacturonan main chain [4]. These side chains can be feruloyl substituted either on O-2 in the main backbone of rhamnogalacturonan-(1, 5)-linked arabinan, on O-5 in the terminal arabinose, or on O-6 in the main backbone of galactan [5]. Most of the ferulic acid ester linked to arabinan and/or galactan can be recovered as ferulate ester of their oligosaccharides under hydrothermal conditions [2].

Feruloyl substitutions can be cross-linked through oxidative coupling reaction (Figure 1) [6,7]. Recently, 8-5' and 8-O-4' were noted as the main ferulate dehydrodimers in covalently cross-linked structures in gelled sugar beet pectin [8]. 


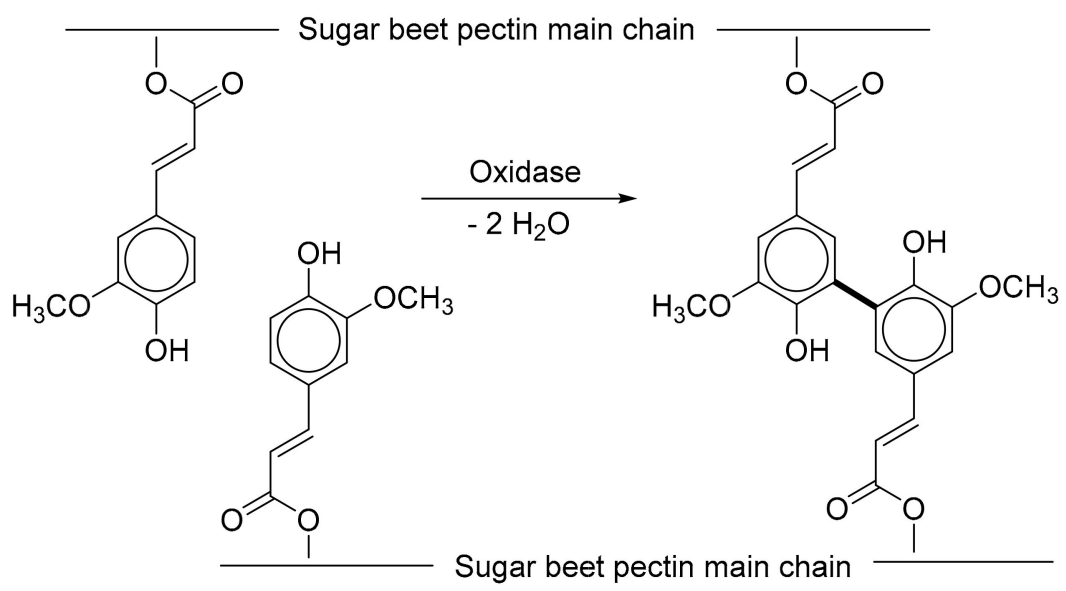

Figure 1. Cross-linking reaction of sugar beet pectins.

Various oxidative agents were applied for the cross-linking of sugar beet pectin gels, including hydrogen peroxide, manganese peroxidases and laccases [9]. Laccases are polyphenol oxidases containing copper atoms in the catalytic centre and reducing oxygen to water accompanied by the oxidation of a phenol substrate [10]. They were suggested as processing aids for wine and beer stabilisation, bakery products, to improve sensory parameters of food, and recently contributed to cross-linked gel formation [11-13].

Formation of a vegan and halal hard gel is a growing issue that has existed for many years, particularly within Europe, with the emergence of bovine spongiform encephalopathy ("mad cow disease") in the 1980s [14]. In the present study, sugar beet fibre, with as many ferulic acid moieties still bound to the sugar chain as possible, was extracted under hydrothermal conditions and cross-linked with a new purified high-redox laccase from the basidiomycete Funalia trogii. The working hypothesis was to convert the abundant side-stream from the sugar refining industry to plant-based gels with a firmness comparable to traditional gelatine gels.

\section{Materials and Methods}

\subsection{Materials}

Dried and ground sugar beet pulp was bought from SternEnzym (Ahrensburg, Germany). All chemicals were obtained from Carl Roth (Karlsruhe, Germany), Fluka (Buchs, Switzerland), and Sigma-Aldrich (Taufkirchen, Germany).

\subsection{Enzymes}

Laccase were purified from the basidiomycete Funalia trogii (DSMZ 11919). For this, the fungus was cultivated in SNL medium [15] and incubated at $25^{\circ} \mathrm{C}$ and $180 \mathrm{rpm}$ for 3 weeks. The purification was done by hydrophobic interaction chromatography on phenyl FF column and ion exchange chromatography on Q-sepharose XL material [16]. The activity of the extracted and purified enzyme was $2.3 \times 10^{5} \mathrm{u} / \mathrm{L}$. Laccase activity was measured at $25{ }^{\circ} \mathrm{C}$ and $\mathrm{pH} 4.5$ using the 2,2'-azino-bis (3-ethylbenzothiazoline-6-sulphonic acid) (ABTS) assay [15].

\subsection{General Experimental Setup}

All data presented are averages of duplicate measurements. The standard deviation of replicates for the rheological measurements was typically below $5 \%$. 


\subsection{Sugar Beet Fibre Extraction}

Sugar beet pulp ( $10 \mathrm{~g})$ was autoclaved at $121{ }^{\circ} \mathrm{C}$ for $20 \mathrm{~min}$ (Laboratory autoclave Biomedis, Giessen, Germany) [17]. Then, a 5\% suspension of sugar beet pulp in water was formed and heated at $95^{\circ} \mathrm{C}$ for $5 \mathrm{~h}$. After cooling to room temperature and filtration $(0.45 \mu \mathrm{m})$, the suspension was centrifuged at $12,000 \times \mathrm{g}$ for $10 \mathrm{~min}$ at $20{ }^{\circ} \mathrm{C}$ (centrifuge $460 \mathrm{R}$ Hettich Rotanta, Taufkirchen, Germany) [18]. The recovered supernatant was concentrated at $50^{\circ} \mathrm{C}$ and vacuum (121 mbar, Heidolph rotary evaporator Laborota 4000, Schwabach, Germany). The concentrated sample was freeze dried (Alpha 1-4 LSCbasic, Martin Christ, Osterode, Germany) and milled manually. The bound ferulic acid content was determined by incubating $2 \mathrm{~mL}$ of $10 \%$ fibrex solution with $2 \mathrm{~mL} \mathrm{KOH} / \mathrm{NaOH}$ (1:1; $4 \mathrm{~mol} / \mathrm{L}$ each) at $50{ }^{\circ} \mathrm{C}$ and $220 \mathrm{rpm}$ for $4 \mathrm{~h}$. The reaction was stopped with $1 \mathrm{~mL} 60 \%$ acetic acid and $5 \mathrm{~mL}$ methanol. After centrifugation at $15,000 \times \mathrm{g}$ and $4{ }^{\circ} \mathrm{C}$ for $15 \mathrm{~min}$, ferulic acid (FA) was analysed by HPLC at $\lambda=323 \mathrm{~nm}$ (SPD-10A VP, Shimadzu Deutschland GmbH, Berlin, Germany) [19].

\subsection{Sugar Beet Fibre Cross-Linking}

In order to crosslink sugar beet fibre (fibrex) gel, a 10\% (w/v) fibrex solution in $0.05 \mathrm{M}$ citrate phosphate buffer $\mathrm{pH} 5.5$ was incubated with laccase $(0.05 \mathrm{U} / \mu \mathrm{g}$ FA, LccFtr) overnight without shaking. The impact of vanillin (4-hydroxy-3-methoxybenaldehyde) (2 and $4 \mathrm{mM})$ as mediator, and citrus peel pectin $(1 \%, 3 \%$ and $5 \%(\mathrm{w} / \mathrm{v}))$ instead of fibrex were likewise investigated.

\subsection{Forming Sweetened Fibrex Gels}

Fibrex gels (10\%) were sweetened by adding $10 \%$ and 30\% D-sucrose and laccase was deactivated under $90 \mathrm{~min}$ heat treatment at $85^{\circ} \mathrm{C}$. Injection of one-unit xylanase activity into the gel and incubation at $30^{\circ} \mathrm{C}$ for $2 \mathrm{~h}$ destroyed the structure of the gels and facilitated the ABTS assay to estimate the residual laccase activity after heat treatment.

In parallel, $6 \%$ gelatin gels (Dr. Oetker, Bielefeld, Germany, as standard), were formed and also heated at $85{ }^{\circ} \mathrm{C}$ for $90 \mathrm{~min}$. All the samples were cooled and stored at $4{ }^{\circ} \mathrm{C}$. Viscoelastic properties of the fibrex gels were compared with gelatin gels prepared with the same buffer and D-sucrose concentrations $(10 \%$ and $30 \%)$ during the 4 weeks storage.

\subsection{Rheology}

To carry out rheological measurements, a Physica MCR 301 rheometer (Anton Paar, Graz, Austria) with plate geometry ( $25 \mathrm{~mm}$ diameter) and a gap width of $1 \mathrm{~mm}$ was used. Oscillation experiments $(\gamma=0.01$ to $100 \%$ ) were performed at a constant frequency of $\omega=10 \mathrm{rad} / \mathrm{s}$ to ascertain the linear viscoelastic region (LVE) [20]. Frequency sweep test used frequencies of 0.01 to $100 \mathrm{~Hz}$ with an applied strain of $5 \%$. All tests were carried out at $25^{\circ} \mathrm{C}$ in duplicates. Rheoplus software was used to calculate storage modulus $\left(\mathrm{G}^{\prime}\right)$, loss modulus $\left(\mathrm{G}^{\prime \prime}\right)$ and loss factor $\tan \delta=\mathrm{G}^{\prime \prime} / \mathrm{G}^{\prime}$.

\subsection{Analysing Diferulic Acids in Fibrex Gels}

\subsubsection{Sample Preparation}

Fibrex gel was enzymatically hydrolysed with $100 \mathrm{U}$ of xylanase:ferulic acid esterase (1:1) mix for $3 \mathrm{~h}$ at $35^{\circ} \mathrm{C}, \mathrm{pH} 6$ and $220 \mathrm{rpm}$. The recombinant ferulic acid esterase originated from Streptomyces werraensis [21]. The hydrolysed sample was purified on $20 \mathrm{~mL}$ XAD 2 resin column as described by Malunga and Beta [22]. Adsorbed diferulic acids were eluted in $30 \mathrm{~mL}$ methanol:formic acid (9:1), concentrated, lyophilised and dissolved in $50 \mu \mathrm{L}$ acetonitrile.

\subsubsection{High Performance Liquid Chromatography Mass Spectrometry}

To detect cross-linked diferulic acids in the gel, $15 \mu \mathrm{L}$ hydrolysate was loaded on a Varian 1200 LC-MS (Agilent, Santa Clara, CA, USA) equipped with a C18 Pyramid column (Macherey-Nagel, 
Düren, Germany). As eluent A, water with $0.1 \%$ formic acid was used, whereas acetonitrile with $0.1 \%$ formic acid was applied as eluent B. A separation was achieved using a stepwise gradient at a flow velocity of $0.1 \mathrm{~mL} / \mathrm{min}$; sample loaded in $10 \%$ eluent $B$, followed by 10 to $100 \%$ eluent $B$ in $20 \mathrm{~min}$, $100 \%$ eluent $B$ for $10 \mathrm{~min}, 100$ to $10 \%$ in $5 \mathrm{~min}$ and ended with $10 \%$ eluent $B$ for $3 \mathrm{~min}$. Mass analysis was performed as follows: needle voltage (+/-) 5000/-4500 V; spray shield voltage (+/-) 600/-600 V; spray chamber temperature $50^{\circ} \mathrm{C}$; drying gas temperature $350{ }^{\circ} \mathrm{C}$; nebulizing gas pressure $379 \mathrm{kPa}$; drying gas pressure $124 \mathrm{kPa}$, and capillary voltage (+/-) 40/-40 V. Mass spectrometry analysis was conducted in a scanning range from 300 to $400 \mathrm{~m} / \mathrm{z}$ for $50 \mathrm{~min}$. In the MS/MS experiments, $10 \mathrm{eV}$ collision energy was chosen to fragment the molecules.

\subsection{Melting Point}

Mechanical spectra of fibrex (10\%) and gelatin gel (6\%) were recorded using a Physica MCR 301 rheometer with plate geometry of $25 \mathrm{~mm}$ diameter and a gap width of $1 \mathrm{~mm}$. The measurement was performed at a temperature rate of $10^{\circ} \mathrm{C} / \mathrm{min}$, angular frequency $101 / \mathrm{s}$ and strain $0.5 \%$, during heating from 20 to $100{ }^{\circ} \mathrm{C}$ for the fibrex gel and 5 to $42{ }^{\circ} \mathrm{C}$ for the gelatin gel. Mechanical parameters were recorded every $0.1 \mathrm{~min}$.

\subsection{Water-Holding Capacity WHC}

In order to conduct the WHC test, $1 \mathrm{~g}$ gel sample (10\%) was centrifuged at $700 \mathrm{~g}$ for $30 \mathrm{~min}$ at $10{ }^{\circ} \mathrm{C}$. The water-holding capacity was calculated as [23]:

$$
\text { WHC }(\%)=(\text { Mass of gel after centrifugation/Mass of gel sample }) \times 100
$$

\subsection{Swelling Ratio}

Fibrex $(10 \%)$ and gelatin gel $(6 \%)$ with a defined volume were immersed in artificial saliva composed as described by Amal et al. [24] for $10 \mathrm{~min}$ at room temperature. The gel volume was measured every two minutes and the swelling ratio calculated as:

$$
\text { Swelling ratio }=\mathrm{V}_{\mathrm{n}} / \mathrm{V}_{0}
$$

where $V_{n}$ is the volume of the gels after every two minutes immersion $\left(\mathrm{m}^{3}\right)$ and $V_{0}$ is the initial volume of the gel before immersion in artificial saliva $\left(\mathrm{m}^{3}\right)$.

\section{Results}

\subsection{Fibrex Gel Characterization}

\subsubsection{Oscillatory Tests on Fibrex Formed with LccFtr and Standard Gelatin Gels}

During a sweep test, the amplitude of the deformation was varied ( $\gamma=0.01$ to $100 \%$ ), while the frequency was kept constant $(\omega=10 \mathrm{rad} / \mathrm{s})$. For the analyses, the storage modulus $\mathrm{G}^{\prime}$ and the loss modulus G" were plotted against the deformation $(\gamma)$. Gels from fibrex $(10 \%)$ and gelatin $(6 \%$ as standard) had constant $G^{\prime}$ and $G^{\prime \prime}$ at $0.1 \leq \gamma \leq 70 \%$, which showed that the sample structures were undisturbed (data not shown). In both, fibrex and gelatin gels, $G^{\prime}$ was $>G^{\prime \prime}$.

Viscoelastic properties derived from a frequency sweep test at $\omega=10 \mathrm{rad} / \mathrm{s}$ presented $\mathrm{G}^{\prime}=5.52 \pm$ 0.023 and $9.05 \pm 0.015 \mathrm{kPa}$ and $\mathrm{G}^{\prime \prime}=1.26 \pm 0.014$ and $2.24 \pm 0.011 \mathrm{kPa}$ for fibrex $(10 \%)$ and gelatin gels $(6 \%)$, respectively.

As can be inferred from Figure 2, the loss factors of both, fibrex and the standard gelatin gels, were $\leq 0.36$, which proved the formation of a solid gel. 


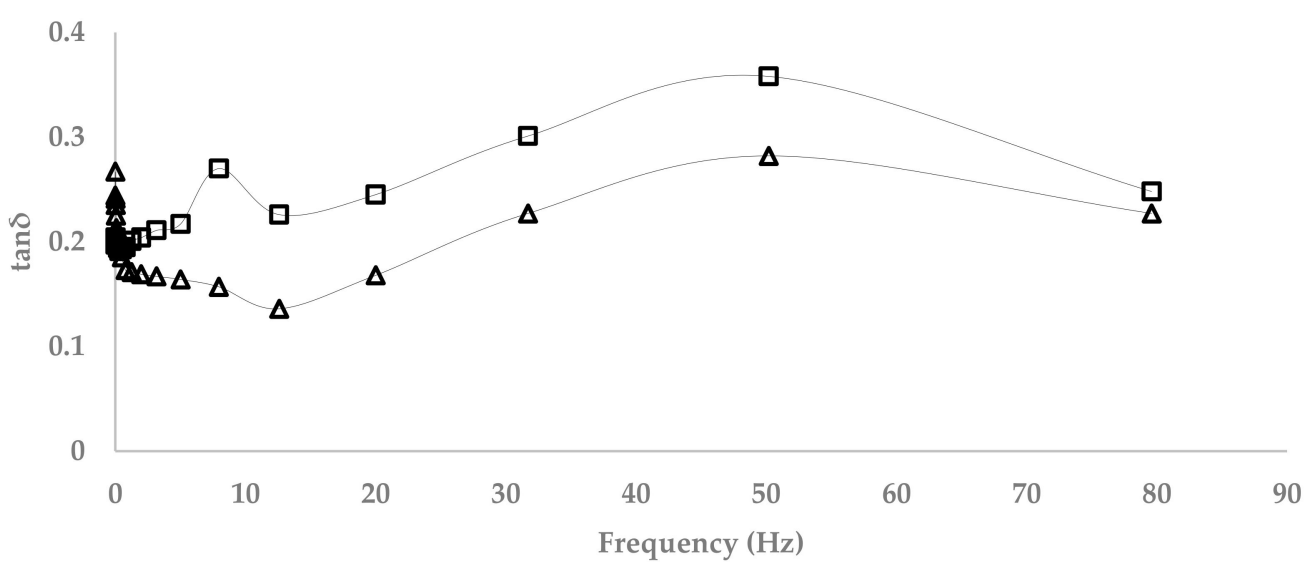

(A)

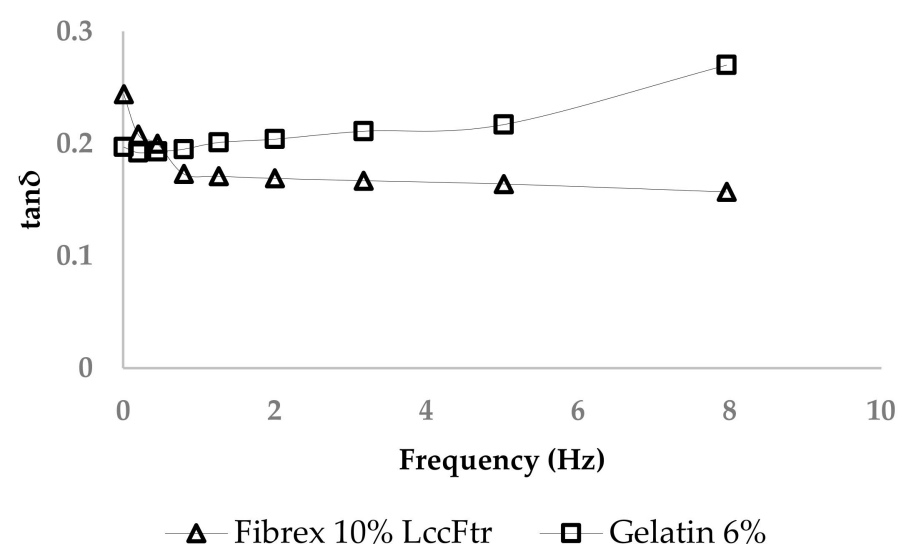

(B)

Figure 2. Loss factors of fibrex gel (10\%) formed with LccFtr, and gelatin gel 6\% (A) in frequencies < $100 \mathrm{~Hz},(\mathbf{B})$ magnifying frequencies $<10 \mathrm{~Hz}$ ).

\subsubsection{Effect of Citrus Pectin and Vanillin on Fibrex Gels}

Different additives were tested to enhance the firmness of the fibrex gels. Table 1 indicates the storage modulus, loss modulus and loss factor of the gels formed in the presence of the presumed reaction mediator vanillin or citrus pectin.

Table 1. Viscoelastic properties of $10 \%$ fibrex gels, storage modulus $\mathrm{G}^{\prime}(\mathrm{kPa})$, loss modulus G" $(\mathrm{kPa})$ and loss factor $\tan \delta$.

\begin{tabular}{|c|c|c|c|c|c|c|}
\hline \multirow{2}{*}{$\begin{array}{l}\text { Rheological } \\
\text { Parameters }\end{array}$} & \multirow{2}{*}{$\begin{array}{c}\text { No } \\
\text { Additives }\end{array}$} & \multicolumn{2}{|c|}{ Vanillin } & \multicolumn{3}{|c|}{ Pectin C } \\
\hline & & $2 \mathrm{mM}$ & $4 \mathrm{mM}$ & $1 \%$ & $3 \%$ & $5 \%$ \\
\hline $\mathrm{G}^{\prime}$ & 5.52 & 1.83 & 1.34 & 5.44 & 5.23 & 5.57 \\
\hline $\mathrm{G}^{\prime \prime}$ & 1.26 & 0.41 & 0.38 & 1.26 & 1.28 & 1.40 \\
\hline $\tan \delta$ & $\leq 0.36$ & $\leq 0.76$ & $\leq 0.80$ & $\leq 0.31$ & $\leq 0.29$ & $\leq 0.30$ \\
\hline
\end{tabular}

Vanillin decreased the storage moduli of the gels and had a destructive effect on the final gel structure at concentrations of two and four mM. Analysing the loss factors of the gels showed much higher values than without vanillin, and the same was true for the viscosity. 
Pectin C ( $1 \%, 3 \%$ and $5 \%)$ was added to improve the viscoelastic properties, but no increase in storage modulus was observed. The rheological examination of the fibrex gels with pectin indicated that the storage moduli were slightly higher in the presence of $5 \%$ pectin than in $1 \%$ and $3 \%$ samples, and all loss factors were $\leq 0.3$. As can be inferred from Table 1 , mediators and pectin $C$ did not improve storage and loss moduli and loss factors of fibrex gels.

\subsection{Viscoelastic Properties of Sweetened Fibrex Gels}

An ABTS assay was performed on sweetened fibrex gels to measure the residual activity of laccase prior to rheological experiments. Approximately $0.03 \%$ of LccFtr activity was left after $90 \mathrm{~min}$ heat treatment at $85^{\circ} \mathrm{C}$ (activity of laccase decreased from 19,800 to $5.4 \mathrm{U} / \mathrm{L}$ ).

The viscoelastic properties of sweetened fibrex $(10 \%)$ and gelatin gels $(6 \%)$ are presented in Table 2. Although neither 10 nor 30\% D-sucrose had a significant impact on storage modulus of fibrex gels, it caused an increase in loss factor of fibrex gels. As can be seen in Table 1 , $\tan \delta$ of fibrex gels with $10 \%$ D-sucrose in week 0 was higher than 1 , which indicated a destruction of the gel structure. Gels containing 30\% D-sucrose were able to maintain their structure. A decrease in storage moduli was observed for sweetened gelatin (mean $G^{\prime}=7.40 \pm 0.50 \mathrm{kPa}$ ) in comparison with non-sweetened gels $\left(G^{\prime}=9.05 \pm 0.015 \mathrm{kPa}\right)$. Loss factors of both sweetened gelatin gels were lower than those of non-sweetened samples with $\tan \delta \leq 0.1$, especially at frequencies between 0.1 to $10 \mathrm{~Hz}$ (Figure 3).

Table 2. Storage modulus $\mathrm{G}^{\prime}(\mathrm{kPa})$, loss modulus $\mathrm{G}^{\prime \prime}(\mathrm{kPa})$ and loss factor tan $\delta$ of $10 \%$ fibrex gels and $6 \%$ gelatin gels (containing D-sucrose) during the 4 -week storage at $4{ }^{\circ} \mathrm{C}$.

\begin{tabular}{|c|c|c|c|c|c|}
\hline Gels & Additives & Week \# & $\mathrm{G}^{\prime}$ & $\mathrm{G}^{\prime \prime}$ & $\tan \delta$ \\
\hline \multirow{6}{*}{$\begin{array}{l}\text { Fibrex gel } 10 \% \\
\text { formed with } \\
\text { LccFtr }\end{array}$} & \multirow{3}{*}{$10 \%$ D-sucrose } & 0 & 5.48 & 1.34 & $\leq 1.73$ \\
\hline & & 2 & 5.36 & 1.43 & $\leq 0.53$ \\
\hline & & 4 & 5.75 & 1.50 & $\leq 0.52$ \\
\hline & \multirow{3}{*}{$30 \%$ D-sucrose } & 0 & 5.27 & 1.33 & $\leq 0.72$ \\
\hline & & 2 & 5.23 & 1.25 & $\leq 0.48$ \\
\hline & & 4 & 5.86 & 1.49 & $\leq 0.66$ \\
\hline \multirow{6}{*}{ Gelatin gel $6 \%$} & \multirow{3}{*}{$10 \%$ D-sucrose } & 0 & 7.90 & 1.51 & $\leq 0.19$ \\
\hline & & 2 & 8.22 & 1.40 & $\leq 0.17$ \\
\hline & & 4 & 6.16 & 1.19 & $\leq 0.20$ \\
\hline & \multirow{3}{*}{$30 \%$ D-sucrose } & 0 & 6.86 & 1.44 & $\leq 0.20$ \\
\hline & & 2 & 6.85 & 1.36 & $\leq 0.19$ \\
\hline & & 4 & 6.46 & 1.23 & $\leq 0.19$ \\
\hline
\end{tabular}

Storage moduli of sweetened fibrex $(10 \%)$ and gelatin $(6 \%)$ gels were investigated during the four-week storage. Although there was a slight reduction (less than $0.12 \mathrm{kPa}$ ) in storage moduli of fibrex gels after two weeks, loss factors have decreased (Table 2). Particularly, loss factor of fibrex gels with $10 \%$ D-sucrose declined from almost 1.8 to 0.5 during the first two weeks of storage, which indicates recovery of the gel structure. Fibrex gels with $30 \%$ of $\mathbf{D}$-sucrose followed the same trend as fibrex gels with $10 \%$ sugar, by a decline in tan $\delta$ from 0.72 to 0.48 (Table 2 and Figure 3). Storage moduli of sweetened fibrex gels experienced a slight raise by the end of week four, which confirmed gel stability during the four-week storage.

As can be inferred from Table 2 and Figure 3 that the viscoelastic properties of sweetened gelatin gels with 10\% D-sucrose increased after 2 weeks of storage. Loss factors of all sweetened gelatin gels remained steady during the four-week storage, although a slight decline of storage moduli was observed in week four. 


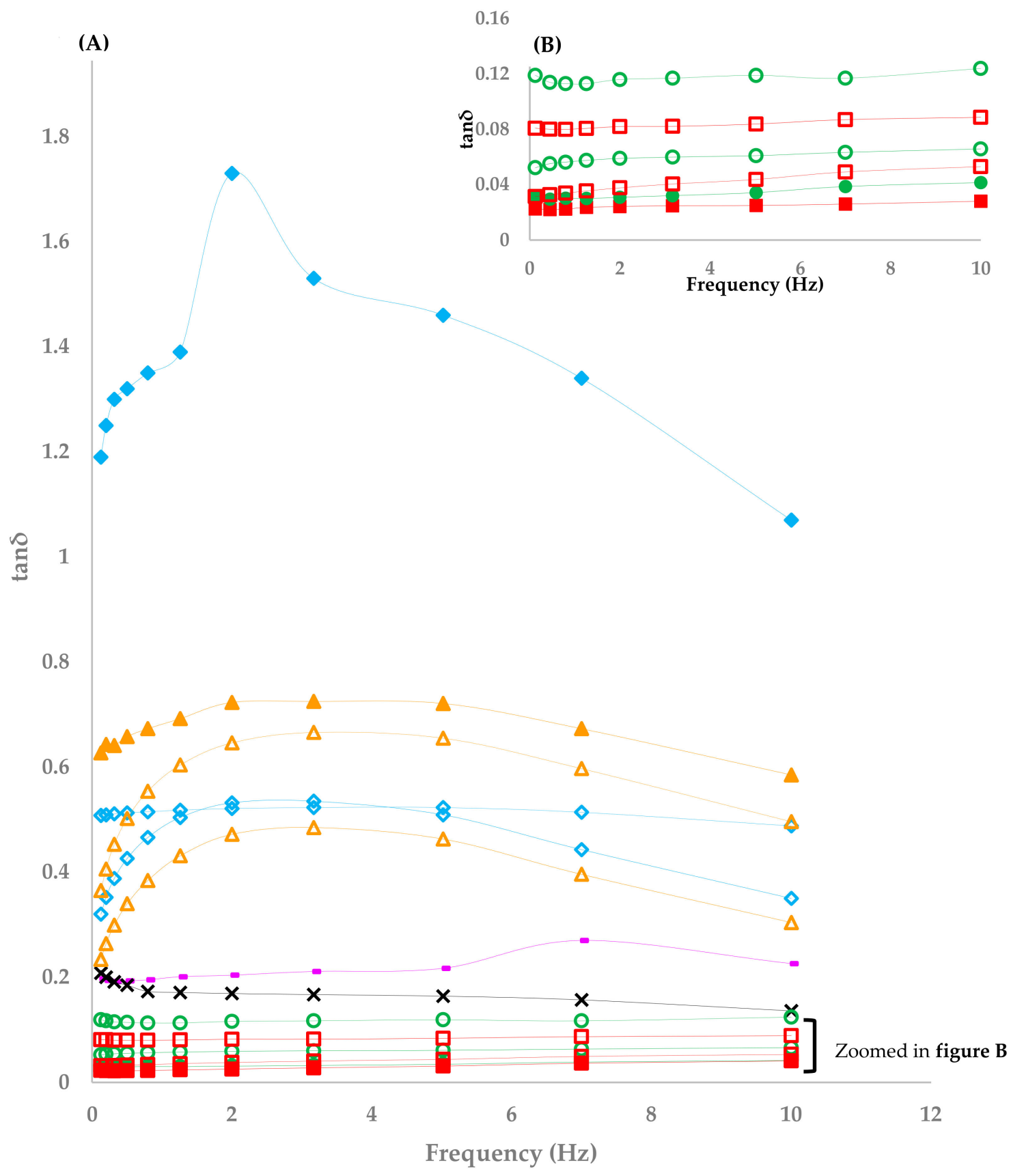

\footnotetext{
- Gelatin gel, No additives $\quad \mathbf{x}$ Fibrex gel, No additives

- Gelatin gel, S. 10\%, W.N. $0 \longrightarrow$ Fibrex gel, S. 10\%, W.N. 0

○ Gelatin gel, S. 10\%, W.N. $2 \diamond$ Fibrex gel, S. 10\%, W.N. 2

- Gelatin gel, S. 10\%, W.N. $4 \triangleleft$ Fibrex gel, S. 10\%, W.N. 4

- Gelatin gel, S. 30\%, W.N. $0-$ Fibrex gel, S. 30\%,W.N. 0

ㅁ Gelatin gel, S. 30\%, W.N. $4 \Delta$ Fibrex gel, S. 30\%, W.N. 2

Gelatin gel, S. 30\%, W.N. $2 \Delta$ Fibrex gel, S. 30\%, W.N. 4
}

Figure 3. (A) Loss factors of fibrex (10\%) formed with LccFtr, and gelatin gels (6\%), containing different concentrations of D-sucrose during four weeks of storage (S.: D-sucrose, W.N.: week number); (B) magnifying loss factor of gelatin gels. 


\subsection{Identifying Diferulic Acids in Cross-Linked Fibrex Gel}

The oxidative gelation of fibrex was supposed to result from the dimerization of FA residues on the polysaccharide chains. The FA dimerization mechanism starts with an abstraction of an $\mathrm{H}$ atom of the $\mathrm{OH}$ group at the ring position of FA leading to a phenoxy radical. Then, this radical is stabilized by resonance along the aromatic ring (C-4/C-5) and the double bond (C-8) of the side chain. Subsequently, two phenoxy or alkoxy radicals cross-link, and the coupling of the unpaired electrons forms a new covalent bond that connects two sugar chains. Consequently, the structure of the dimers formed during gelation depends on the radical position [13,25].

Liquid chromatography mass spectrometry (LC-MS) showed a peak (retention time about $14.3 \mathrm{~min}$ ) with $\mathrm{m} / \mathrm{z} 387(+)$, indicative of a diferulic acid [26]. An MS/MS fragmentation experiment on this peak led to fragment ion masses m/z $351\left(-2 \mathrm{H}_{2} \mathrm{O}\right), 343$ (-COO-), $325\left(-\mathrm{H}_{2} \mathrm{O}-\mathrm{COO}-\right), 307\left(-2 \mathrm{H}_{2} \mathrm{O}-\mathrm{COO}-\right)$, $293\left(-\mathrm{H}_{2} \mathrm{O}-\mathrm{COO}-\mathrm{CH}_{3} \mathrm{OH}-\right), 265\left(-\mathrm{H}_{2} \mathrm{O}-\mathrm{CO}-\mathrm{COO}-\mathrm{CH}_{3} \mathrm{OH}-\right), 219\left(-\mathrm{H}_{2} \mathrm{O}-\mathrm{CO}-\mathrm{COO}-\mathrm{COO}-\mathrm{CH}_{3} \mathrm{OH}-\right)$ and $201\left(-2 \mathrm{H}_{2} \mathrm{O}-\mathrm{CO}-\mathrm{COO}-\mathrm{COO}-\mathrm{CH}_{3} \mathrm{OH}-\right)$, which fit to 8-5' diferulic acid (Figure 4).<smiles></smiles>

Figure 4. Molecular structure of 8-5' diferulic acid.

\subsection{Melting Point}

Figures 5 and 6 present the temperature dependence of the dynamic modulus $\left(G^{\prime}\right.$ and $\left.G^{\prime \prime}\right)$ during isochronal temperature sweeps from 5 to $42{ }^{\circ} \mathrm{C}$ and 20 to $100{ }^{\circ} \mathrm{C}$ for gelatin and fibrex gels, respectively. The starting temperature was chosen according to the gel formation temperature. Measurements were conducted by a constant frequency oscillatory test.

Storage modulus of gelatin gels gradually decreased by increasing the temperature from 5 to $30{ }^{\circ} \mathrm{C}$, followed with a sudden drop at around $32{ }^{\circ} \mathrm{C}$ (Figure 5). The melting point of gelatin is $\leq 35{ }^{\circ} \mathrm{C}$, however it depends on its grade and concentration [27]. As shown in Figure 6, the storage modulus of fibrex gels slightly increased with increasing temperatures $\left(0.003 \mathrm{kPa} /{ }^{\circ} \mathrm{C}\right)$, and there was a correlation between rising temperature and storage modulus alteration with $R^{2}=0.89$.

\subsection{Water-Holding Capacity}

Water holding capacity is a physical property that prevents water from being released from the structure of the gel [28]. The water holding capacities for fibrex (10\%) and gelatin $(6 \%)$ gels were determined to be $98.5 \%$ and $98.6 \%$, respectively.

\subsection{Swelling Ratio}

Figure 7 presents the swelling ratio of gelatin $(6 \%)$ and fibrex $(10 \%)$ gels. A linear correlation $\left(R^{2}=0.98\right)$ between swelling ratio of the fibrex gel and immersion time in artificial saliva was recorded. In contrast, the gelatin gel structure was broken after five minutes storage at room temperature. 


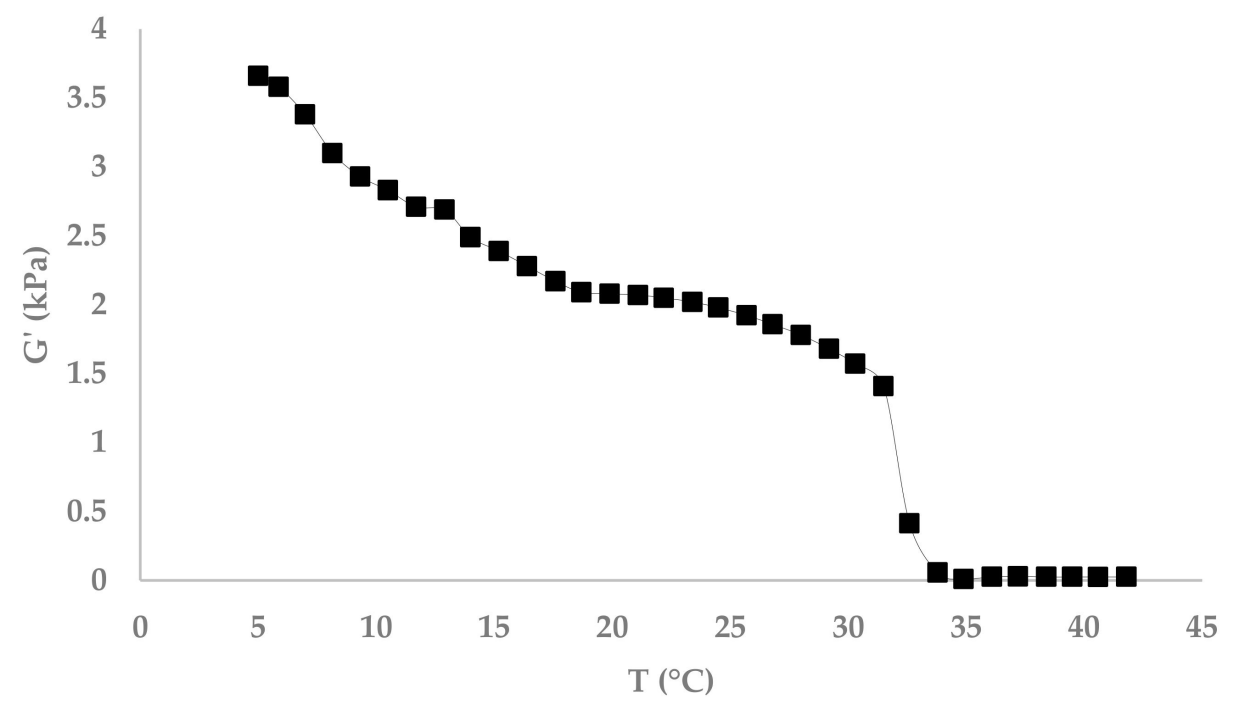

(A)

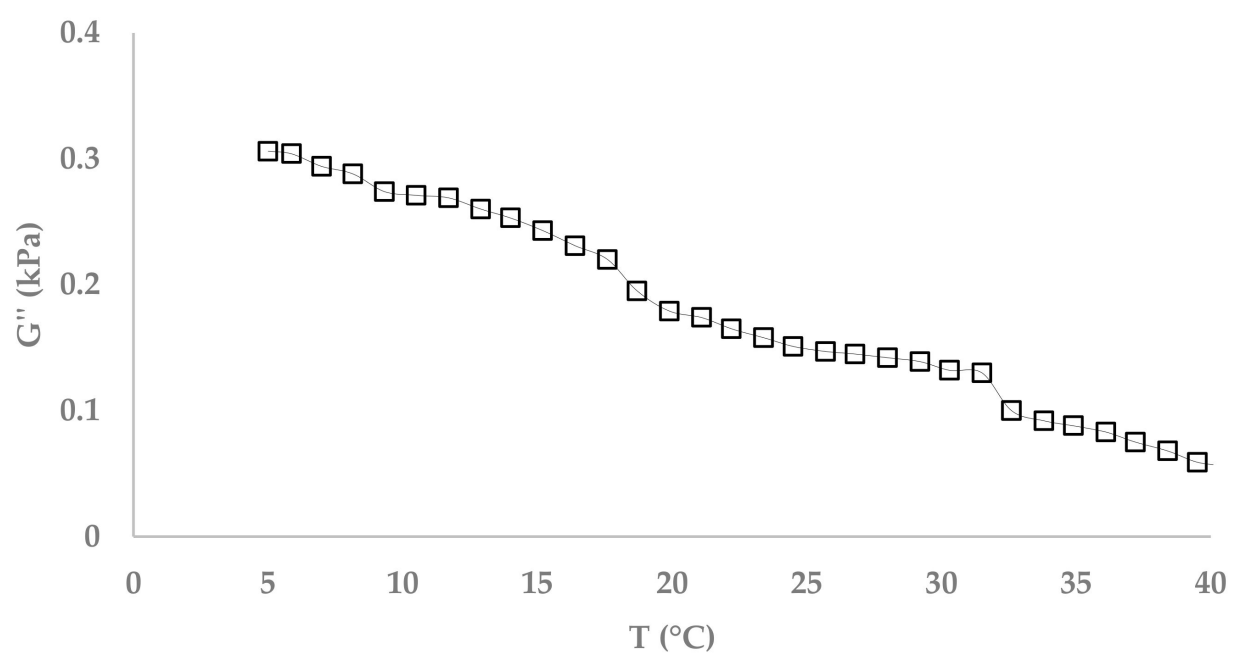

(B)

Figure 5. Melting point of gelatin gel (6\%); (A) storage modulus, (B) loss modulus. 


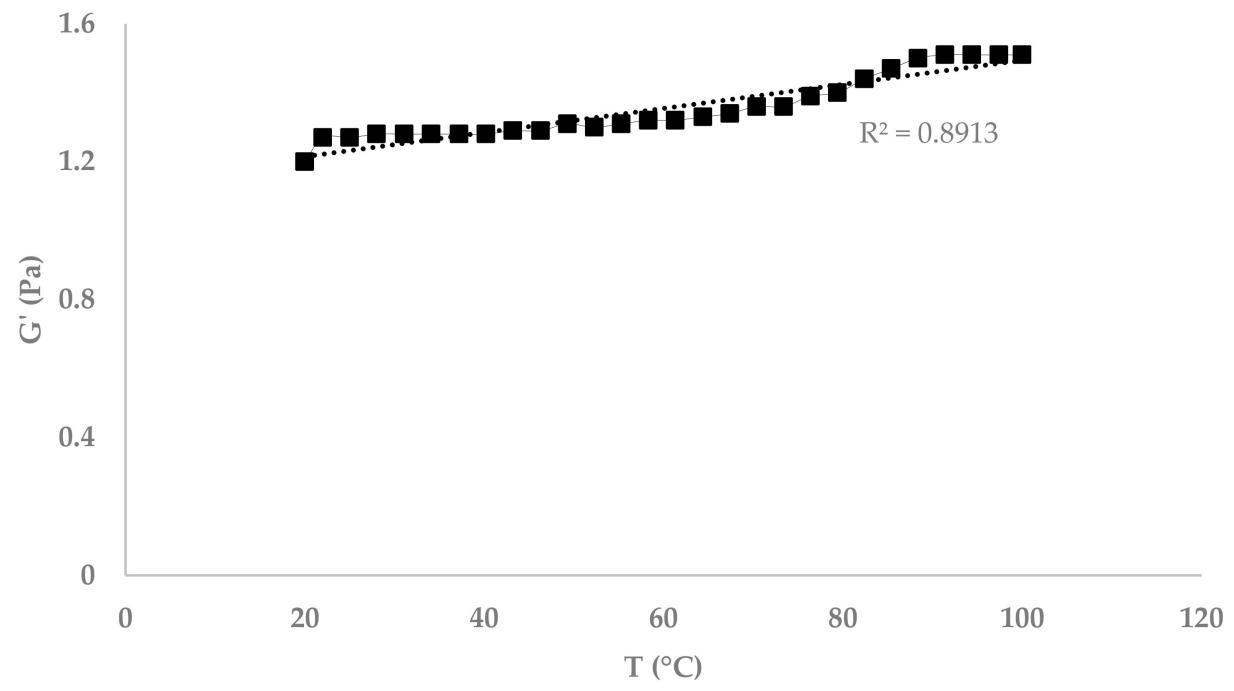

(A)

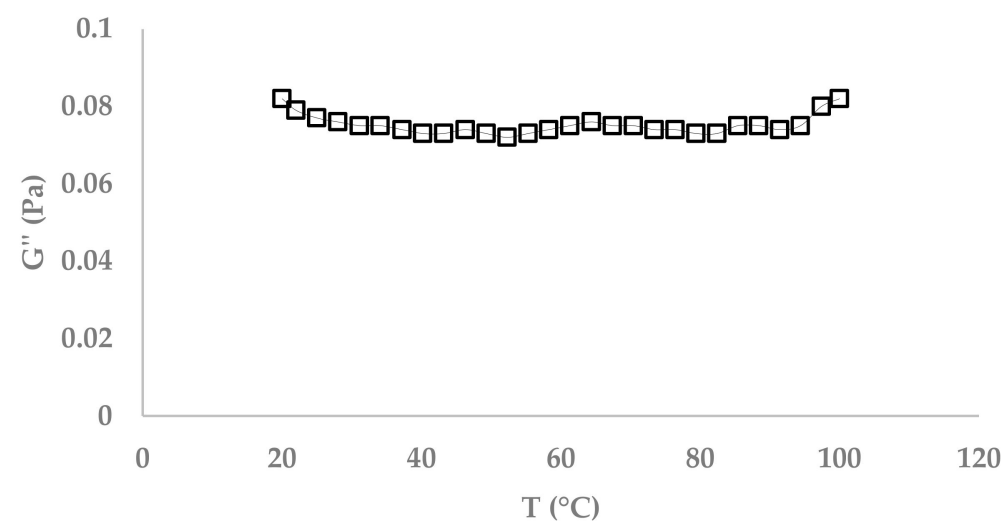

(B)

Figure 6. Melting point of fibrex gel (10\%); (A) storage modulus, (B) loss modulus.

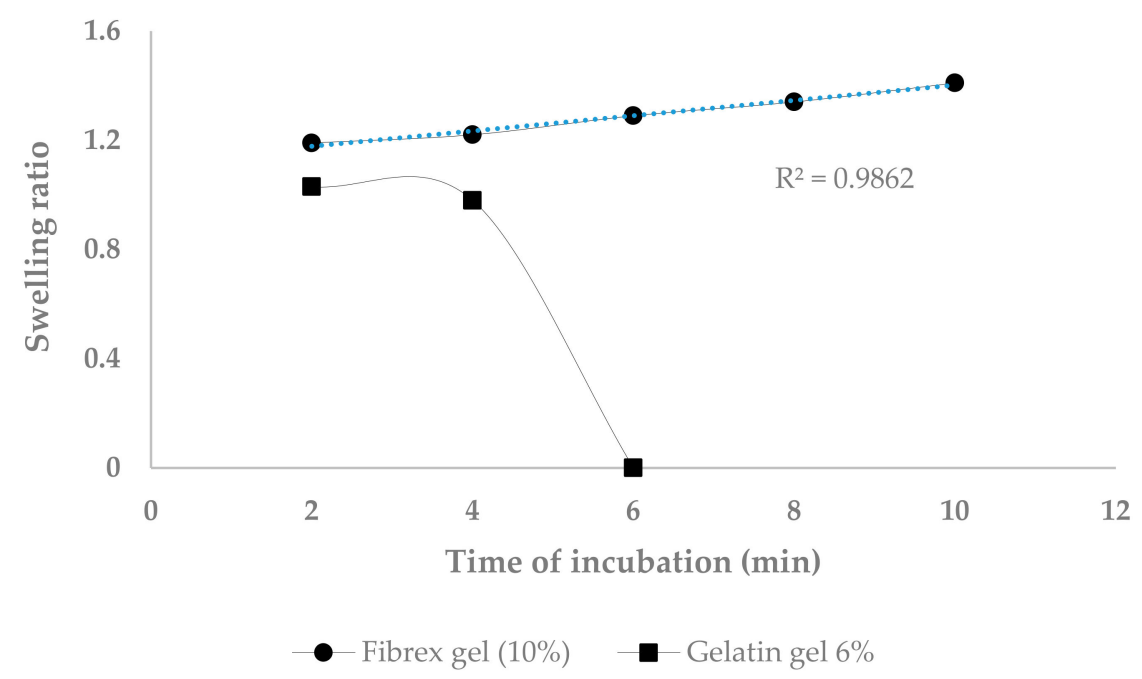

Figure 7. Swelling ratio of gelatin $(6 \%)$ and fibrex gel $(10 \%)$ in artificial saliva at room temperature. 


\section{Discussion}

\subsection{Fibrex and Gelatin Gel Characterization}

Rheological experiments on fibrex and gelatin gels showed that $\mathrm{G}^{\prime}>\mathrm{G}^{\prime \prime}$. A larger storage modulus than loss modulus indicates viscoelastic behaviour of the gels [20]. According to the results, although the storage modulus of fibrex gels was lower than that of gelatin gels, a firm and stable cross-linked gel was formed owing to bound ferulic acid moieties [29]. Ferulic acid content of the self-extracted fibrex in the current study was $1.98 \pm 0.04 \mu \mathrm{g} / \mathrm{mg}$, which was $0.19 \mu \mathrm{g} / \mathrm{mg}$ lower than the ferulic acid content in the self-extracted arabinoxylan in a previous study [13]. The higher storage modulus of cross-linked arabinoxylan gel than fibrex gel can be attributed to the lower ferulic acid content of the extracted fibrex [13]. In addition, laccases from Pleurotus pulmonarius (LccPpu) as well as Funalia trogii successfully cross-linked arabinoxylan gels, while laccase Ppu did not form a hard fibrex gel [13], an indication of a different enzyme specificity. Both fibrex and standard gelatin gels had loss factor lower than one ( $\tan \delta \leq 0.36$ ), which proved viscoelastic properties (Figure 2) [30].

\subsection{Effect of Citrus Pectin and Vanillin on Fibrex Gels}

Although citrus pectin is known as a common thickening and gelling agent to link with various compounds to form a gel [31], it did not significantly affect the rheological properties of fibrex gels (Table 1). It appeared that the addition of pectin resulted in hydrogen bonds and hydrophobic interactions in the gel, instead of increasing covalently cross-linked bonds [8].

Vanillin is a flavouring agent and effectively contributed to some laccase mediator system [32]. However, it had a destructive impact on the mechanical spectra of the cross-linked fibrex gel. The phenolic compound may have impeded gelation by quenching ferulic acid radicals [33].

\subsection{Viscoelastic Properties of Sweetened Fibrex and Gelatin Gels}

A heat treatment and cooling procedure was applied to deactivate the laccase prior to viscoelastic analysis of sweetened gels. Although a significant decrease in laccase activity was observed, a residual activity of $3.1 \times 10^{-5} \mathrm{U} / \mu \mathrm{g}$ FA remained. Laccases from white rot fungus are typically stable within temperatures of $20-50{ }^{\circ} \mathrm{C}$. The half-life of crude LccFtr was reported to be about five minutes at $70{ }^{\circ} \mathrm{C}$ [34]. However, the residual activity of the enzyme revealed that LccFtr resisted higher temperatures $\left(85^{\circ} \mathrm{C}\right)$ when enclosed in the gel structure.

Analysing viscoelastic properties of sweetened gels indicated that the tan $\delta$ of fibrex gels with $10 \%$ D-sucrose in week zero was higher than in one, which indicates destruction of the gel structure (Table 2). This was attributed to the competition between D-sucrose and hydrocolloids for the available water in the system. It was reported that higher concentrations of D-sucrose interrupted this phenomenon in some gel matrices [35]. This would explain the unbroken gel structure in fibrex gels containing 30\% D-sucrose. Krnic et al. found that the common concentration of sugar in jelly confectionary was $30 \%$ of D-sucrose, which is usually combined with other sweeteners, such as glucose [36]. As it can be inferred from the results, 30\% of D-sucrose produces a firm gel.

Sweetened fibrex gels with $10 \%$ and $30 \%$ D-sucrose followed the same trend after two weeks of storage (Table 2). Loss factors of the gels at frequencies between 0.1 to $10 \mathrm{~Hz}$ decreased in week two (Figure 3). This behaviour may result from the slow immobilization of free water and rearrangement of cross-linked junction zones [37]. Table 2 shows an enhancement in storage modulus of the sweetened fibrex gels after four weeks of storage. However, some softening of the structure was observed, owing to an increase in loss factors of the fibrex gels (30\% D-sucrose) in week four (Figure 3). Residual radicals produced by the laccase were probably responsible for this phenomenon. Participating in secondary reactions, these may have led to the beginning of degradation of the fibrex main chains [38].

The loss factors of sweetened gelatin gels were lower than that of non-sweetened samples with $\tan \delta \leq 0.1$, especially at frequencies between 0.1 to $10 \mathrm{~Hz}$ (Figure 3). This represented a more elastic behaviour of the sweetened gelatin gels [39]. Added sugar led to smaller but more numerous 
junction zones, thus producing a more extended gel network and increasing the rigidity of the gel [40]. Loss factors of all sweetened gelatin gels remained steady after four weeks of storage, despite a slight decline in storage moduli in week four.

There are two important steps during the gelatin gelation process: setting and ageing. Setting involves network formation throughout the gelatin solution. During ageing, gel strength develops at a constant temperature and only the strongest bonds survive [41]. Reduction of the storage modulus in gelatin gels containing $\mathrm{D}$-sucrose lower than $20 \%$ can result from the increased distance between molecular chains during ageing, which decrease the number of entangles points in the gelatin networks [42]. On the other hand, textural analysis of gelatin gels in presence of $0-40 \%$ D-sucrose and glucose syrup indicated an increase in gumminess and hardness, when compared to samples with no sugars. In the study, sugars were shown to have a stronger effect on textural properties than the gelatin concentration [43].

As it becomes evident from Figure 3, sweetened fibrex gels had higher loss factors than fresh non-sweetened fibrex gels, in contrast to sweetened gelatin gels, which showed lower loss factor than fresh non-sweetened gel samples. D-sucrose may shrink cross-linking enhancement by trapping available water in the system, which caused a minor rise in $\tan \delta$. Otherwise, added sugar declined $\tan \delta$ in gelatin gels by growing junction zones, producing more extended gel networks, and increasing the rigidity of the gel [44]. Both fibrex and gelatin gels stayed stable during four weeks of storage. They all showed loss factors $<1$ at week 4 , which confirmed their elastic properties. Moreover, it was reported that sweetened gelatin gels have stable viscoelastic and physical properties during 30-days cold storage $\left(4^{\circ} \mathrm{C}\right)[37]$.

\subsection{Identifying Diferulic Acids in Cross-Linked Fibrex Gel}

The fibrex gelation process and gel properties were governed by the establishment of covalent (di-FA, tri-FA bridges) linkages [45]. Analysing diferulic acids in the fibrex gels cross-linked with LccFtr proved the presence of 8-5' ferulic acid dehydrodimers. Dominating dimers of ferulic acids in cross-linked fibrex gel were 8-O-4' and 8-5', which increased after gel formation [29]. Recently, formation of cross-links of ferulic acid of higher molecular masses than dimers and undefined superior structures was also reported [25].

In a recent study, another fungal laccase, laccase Ppu, was applied to cross-link arabinoxylan gels. LCMS/MS analysis of the cross-linked arabinoxylan gel demonstrated that 8-O-4' dimers of ferulic acids predominated [13]. In contrast, laccase Ftr, which has been applied to cross-link fibrex gels, produced 8-5' diferulic acids. This is most likely based on different substrate specificities; Laccase Ftr formed phenoxy radicals by absorption of the $\mathrm{H}$ atom of the $\mathrm{OH}$ group at the $\mathrm{C}-5$ ring position of ferulic acid, while laccase Ppu preferred the C-4 ring position.

\subsection{Fibrex and Gelatin Gel Structural Characteristics}

Melting point, water holding capacity and swelling ratio were the investigated structural characteristics in fibrex and gelatin gels.

Gelatin gels are known to be melted at body temperature [46], and as is shown in Figure 5, loss modulus overtakes storage modulus at temperature higher than $35^{\circ} \mathrm{C}$. In contrast, cross-linked fibrex gels demonstrated a heat resistant property (Figure 6). The higher temperature stability of the fibrex gel resulted from the covalent bonds formed after oxidative coupling of the ferulic acids. The covalent structure gave some unique characteristics to the gels, such as high water absorption capacity and stability to $\mathrm{pH}$, temperature and ionic charges [25].

High water holding capacity is a unique characteristic in oxidative cross-linked gels. The high WHC of fibrex gels, which equalled that of the gelatin gel, resulted from the three-dimensional network that was able to retain a large aqueous phase and provided a structure stable against syneresis and shrinkage [25]. In a recent study, high WHC of arabinoxylan gels, which are also based on the cross-linking of diferulic acids, was also proven [13]. 
Fibrex gels demonstrated a swelling ratio with a linear correlation $\left(R^{2}=0.98\right)$ (Figure 7). In contrast, gelatin gels experience a collapse in gel structure owing to dissolving hydrogen bonds during immersion in saliva. This was attributed to the penetration of water molecules into the gel network and dissolving hydrogen bonds. Cross-linked gels are known for their higher stability towards swelling [47]. It was reported that swelling ratio in some cross-linked gels was higher than theoretically determined from the diferulic acid content. It was suggested that, in addition to di-FA and tri-FA, higher ferulated cross-linking and physical entanglements would contribute to the final gel structures [48].

\section{Conclusions}

The present study showed that sugar beet fibre obtained by a modified hydrothermal extraction method was successfully cross-linked with purified laccases from Funalia trogii. Although the storage modulus of the final gel was not as high as in gelatin gels, it had loss factors $<0.4$, which proved the elastic properties of the fibrex gels. An enhancement of the cross-linking effect, using vanillin as a food-grade mediator and flavour, or citrus pectin, was unsuccessful.

Adding D-sucrose as a sweetener not only decreased the storage modulus of fibrex gels, but also doubled the loss factor. This was in contrast to gelatin gels, which showed lower loss factors than non-sweetened gelatin gels. Sweetened gels retained their rheological properties during a storage period of 28 days at $5{ }^{\circ} \mathrm{C}$.

Fibrex, as a high amount side-stream of the refining sugar industry, formed a hard edible gel via covalent cross-links. Formation of $8-5^{\prime}$ dehydrodimers of ferulic acids governed the formation of the cross-linked fibrex gels. The gels demonstrated viscoelastic gel characteristics, including heat resistance, high swelling ratio and water holding capacity. Cross-linking of fibrex effectively altered the industrial side-stream to a firm, heat resistant gel, formed at room temperature, which could be applied in pharmaceutical and other industries.

The enzymatic cross-linking concept appears promising to provide gels with special textural features. Sensory tests must be performed to investigate the organoleptic properties of the gels including the release of volatile and non-volatile ingredients typically contained in foods, such as candies, confectionary, liquorice products, glaze and desserts.

Author Contributions: S.K. and R.G.B. conceived and designed the experiments; S.K. performed the experiments; S.K. analysed the data; R.G.B. and F.E. contributed to materials and analysis tools; S.K. and F.E. wrote the paper. All authors have read and agreed to the published version of the manuscript.

Funding: This research did not receive any specific grant from funding agencies in the public, commercial or not-for-profit sectors.

Acknowledgments: The authors are grateful to U. Krings at the Institute of Food Chemistry, LU Hannover, for his skilful mass spectrometric analyses and help with the interpretation of the MS/MS data. We also thank T. Detering for the helpful assistance. The publication of this article was funded by the Open Access fund of the Leibniz Universität Hannover.

Conflicts of Interest: The authors have no affiliation with any organization with a direct or indirect financial interest in the subject matter discussed in the manuscript.

\section{References}

1. Michel, F.; Thibault, J.; Barryb, J. Preparation and characterisation of dietary fibre from sugar beet pulp. J. Sci. Food Agric. 1987, 42, 77-85. [CrossRef]

2. Sato, N.; Takano, Y.; Mizuno, M.; Nozaki, K.; Umemura, S.; Matsuzawa, T.; Amano, Y.; Makishima, S. Production of feruloylated arabino-oligosaccharides (FA-AOs) from beet fiber by hydrothermal treatment. J. Supercrital Fluids 2013, 79, 84-91. [CrossRef]

3. Pacheco, M.; Villamiel, M.; Moreno, R.; Moreno, F. Structural and rheological properties of pectins extracted from industrial sugar beet by-products. Molecules 2019, 24, 392. [CrossRef] [PubMed]

4. Saulnier, L.; Thibault, J.F. Review ferulic acid and diferulic acid as components of sugar beet pectins and maize bran heteroxylan. J. Sci. Food Agric. 1999, 79, 396-402. [CrossRef] 
5. Holck, J.; Lorentzen, A.; Vigsnaes, L.K.; Licht, T.R.; Mikkelsen, J.D.; Meyer, A.S. Feruloylated and Nonferuloylated Arabino-oligosaccharides from Sugar Beet Pectin Selectively Stimulate the Growth of Bifidobacterium spp. in Human Fecal in Vitro Fermentations. J. Agric. Food Chem. 2011, 59, 6511-6519. [CrossRef]

6. Liu, L.; Fishman, M.; Kost, J.; Hicks, K. Pectin based systems for colon specific drug delivery via oral route. Biomaterials 2003, 24, 3333-3343. [CrossRef]

7. Levigne, S.; Ralet, M.C.; Quemener, B.; Thibault, J.F. Isolation of diferulic bridges ester linked to arabinan in sugar beet cell walls. Carbohydr. Res. 2004, 339, 2315-2319. [CrossRef]

8. Gawkowska, D.; Cybulska, J.; Zdunek, A. Structure-related gelling of pectins and linking with other natural compounds: A review. Polymers 2018, 10, 762. [CrossRef]

9. Kuuva, T.; Lantto, R.; Reinikainen, T.; Buchert, J.; Autio, K. Rheological properties of laccase-induced sugar beet pectin gels. Food Hydrocoll. 2003, 17, 679-684. [CrossRef]

10. Baldrian, P. Fungal laccases-occurrence and properties. FEMS Microbiol. Rev. 2006, 30, 215-242. [CrossRef]

11. Osma, J.F.; Toca-Herrera, J.L.; Rodríguez-Couto, S. Uses of Laccases in the Food Industry. Enzym. Res. 2010, 1-8. [CrossRef] [PubMed]

12. Ayala-Soto, F.E.; Serna-Saldivar, S.O.; Welti-Chanes, J. Effect of processing time, temperature and alkali concentration on yield extraction, structure and gelling properties of corn fiber arabinoxylans. Food Hydrocoll. 2016, 60, 21-28. [CrossRef]

13. Khalighi, S.; Berger, R.G.; Ersoy, F. Cross-linking of wheat bran arabinoxylan by fungal laccases yields firm gels. Processes 2019. under review.

14. Morrison, N.A.; Clark, R.C.; Chen, Y.L.; Talashek, T.; Sworn, G. Gelatin alternatives for the food industry. In Physical Chemistry and Industrial Application of Gellan Gum; Progress in Colloid and Polymer Science; Nishinari, K., Ed.; Springer: Berlin/Heidelberg, Germany, 1999; Volume 114, ISBN 978-3-540-48349-6.

15. Struch, M.; Linke, D.; Mokoonlall, A.; Hinrichs, J.; Berger, R.G. Laccase catalyzed crosslinking of skimmed milk yoghurt enhanced by food-grade mediators. Int. Dairy J. 2015, 49, 89-94. [CrossRef]

16. Kolwek, J.; Behrens, C.; Linke, D.; Krings, U.; Berger, R.G. Cell-free one-pot conversion of (+)-valencene to (+)-nootkatone by a unique dye-decolorizing peroxidase combined with a laccase from Funalia trogii. J. Ind. Microbiol. Biotechnol. 2018, 45, 89-101. [CrossRef] [PubMed]

17. Guillon, F.; Barry, J.; Thibault, J. Effect of autoclaving sugar-beet fibre on its physico-chemical properties and its in-vitro degradation by human faecal bacteria. J. Sci. Food Agric. 1992, 60, 69-79. [CrossRef]

18. Yapo, B.M.; Robert, C.; Etienne, I.; Wathelet, B.; Paquot, M. Effect of extraction conditions on the yield, purity and surface properties of sugar beet pulp pectin extracts. Food Chem. 2007, 100, 1356-1364. [CrossRef]

19. Nieter, A.; Kelle, S.; Linke, D.; Berger, R.G. Feruloyl esterases from Schizophyllum commune to treat food industry side-streams. Bioresour. Technol. 2016, 220, 38-46. [CrossRef]

20. Barnes, H.A. A Handbook of Elementary Rheology; The University of Wales, Institute of Non-Newtonian Fluid Mechanics, Department of Mathematics: Cardiff, UK, 2000; Chapter 6; ISBN 92-5-101137-0.

21. Schulz, K.; Nieter, A.; Scheu, A.K.; Copa-Patiño, J.L.; Popper, L.; Berger, R.G. A type D ferulic acid esterase from Streptomyces werraensis affects the volume of wheat dough pastries. Appl. Microbiol. Biotechnol. 2018, 102, 1269-1279. [CrossRef]

22. Malunga, L.N.; Beta, T. Isolation and identification of feruloylated arabinoxylan mono- and oligosaccharides from undigested and digested maize and wheat. Heliyon 2016, 2, e00106. [CrossRef]

23. Chen, M.J.; Lin, C.W. Factors Affecting the Water-Holding Capacity of Fibrinogen/Plasma Protein Gels Optimized by Response Surface Methodology. J. Food Sci. 2002, 67, 2579-2582. [CrossRef]

24. Amal, A.; Hussain, S.; Jalaluddin, M. Preparation of artificial saliva formulation. Int. Conf. ICB Pharma II 2015, A002, 6-12.

25. Mendez-Encinas, M.A.; Carvajal-Millan, E.; Rascon-Chu, A.; Astiazaran-Garcia, H.F.; Valencia-Rivera, D.E. Ferulated Arabinoxylans and Their Gels: Functional Properties and Potential Application as Antioxidant and Anticancer Agent. Hindawi Oxidative Med. Cell. Longev. 2018, 2018, 2314759. [CrossRef] [PubMed]

26. Vismeh, R.; Lu, F.; Shishir, P.S.; Chundawat, S.; Humpula, J.F.; Azarpira, A.; Balan, V.; Dale, B.E.; Ralph, J.; Jones, A.D. Profiling of diferulates (plant cell wall cross-linkers) using ultrahigh-performance liquid chromatography mass spectrometry. Analyst 2013, 138, 6683-6692. [CrossRef] [PubMed]

27. Francis, F.J. Wiley Encyclopaedia of Food Science and Technology, 2nd ed.; Francis, F.J., Ed.; John Wiley \& Sons Inc.: London, UK, 1999; Volume 4, ISBN 978-0-471-19285-5. 
28. Zayas, J.F. Water Holding Capacity of Proteins. In Functionality of Proteins in Food; Springer: Berlin/Heidelberg, Germany, 1997; ISBN 978-3-642-63856-5.

29. Oosterveld, A.; Grabber, J.; Beldman, G.; Ralph, J.; Voragen, A. Formation of ferulic acid dehydrodimers through oxidative cross-linking of sugar beet pectin. Carbohydr. Res. 1997, 300, 179-181. [CrossRef]

30. Eidam, D.; Kulicke, W.M.; Kuhn, K.; Stute, R. Formation of maize starch gels selectively regulated by the addition of hydrocolloids biosynthesis. Starch Stärke 1995, 47, 378-384. [CrossRef]

31. Saha, D.; Bhattacharya, S. Hydrocolloids as thickening and gelling agents in food: A critical review. J. Food Sci. Technol. 2010, 47, 587-597. [CrossRef]

32. Weiss, J.; Mokoonlall, A.; Sykora, L.; Pfannstiel, J.; Stefan, N.; Hinrichs, J. A feasibility study on the application of a laccase-mediator system in stirred yoghurt at the pilot scale. Food Hydrocoll. 2016, 60, 119-127.

33. Figueroa-Espinoza, M.C.; Rouau, X. Effect of cysteinyl caffeic acid, caffeic acid, and L-dopa on the oxidative cross-linking of feruloylated arabinoxylans by a fungal laccase. J. Agric. Food Chem. 1999, 47, 497-503. [CrossRef]

34. Yesilada, O.; Birhanli, E.; Ozmem, N.; Ercan, S. Highly stable laccase from repeated-batch culture of Funalia trogii ATCC 200800. Appl. Biochem. Microbiol. 2014, 50, 55-61. [CrossRef]

35. Tabilo-Munizaga, G.; Saenz-Hernandez, C.; Herrera-Lavados, C. Influence of temperature, calcium and sucrose concentration on viscoelastic properties of Prosopis chilensis seed gum and nopal mucilage dispersions. Int. J. Food Sci. Technol. 2018, 53, 1781-1788. [CrossRef]

36. Krnic, P.; Truman, P.; Bates, D.; Vilkhu, K. Method for the Production of Jelly Confectionary. U.S. Patent 8895093, 25 November 2014.

37. Cheng, L.; Yang, H. Effect of salt and sugar addition on the physicochemical properties and nanostructure of fish gelatin. Food Hydrocoll. 2015, 45, 72-82.

38. Morales-Burgos, A.M.; Carvajal-Millan, E.; Lopez-Franco, Y.; Rascon-Chu, A.; Lizardi-Mendoza, J.; Sotelo-Cruz, N.; Brown-Bojorquez, F.; Burgara-Estrella, A.; Pedroza-Montero, M. Syneresis in gels of highly ferulated arabinoxylans: Characterization of covalent cross-linking, rheology, and microstructure. Polymers 2017, 9, 164. [CrossRef] [PubMed]

39. Fu, J.; Rao, M. Rheology and structure development during gelation of low-methoxyl pectin gels: The effect of sucrose. Food Hydrocoll. 2001, 15, 93-100. [CrossRef]

40. Oakenfull, D.; Scott, A. Stabilization of gelatin gels by sugars and polyols. Food Hydrocoll. 1986, 1, $163-175$. [CrossRef]

41. Burey, P.; Bhandari, R.; Rutgers, R.P.G.; Halley, P.J.; Torley, P.J. Confectionery Gels: A Review on Formulation, Rheological and Structural Aspects. Int. J. Food Prop. 2010, 12, 176-210. [CrossRef]

42. Kuan, Y.; Mohammadi, A.; Huda, N.; Arif, F.; Karim, A. Effect of sugars on the gelation kinetics and texture of duck feet gelatin. Food Hydrocoll. 2016, 58, 267-275. [CrossRef]

43. Porayanee, M.; Katemake, P.; Duangmal, K. Effect of gelatin concentrations and glucose syrup to sucrose ratios on textural and optical properties of gelatin gel. Int. J. Food Sci. Technol. 2015, 1, 26-30.

44. Kamer, D.D.; Palabiyik, I.; Isik, N.O.; Akyuz, F.; Demiric, A.S.; Gumus, T. Effect of confectionery solutes on the rheological properties of fish (Oncorhynchus mykiss) gelatin. LWT Food Sci. Technol. 2019, 101, 499-505. [CrossRef]

45. Norulfairuz, D.; Zaidel, A.; Chronakis, I.; Meyer, A. Food hydrocolloids enzyme catalysed oxidative gelation of sugar beet pectin: Kinetics and rheology. Food Hydrocoll. 2012, 28, 130-140.

46. Karim, A.; Bhat, R. Gelatin alternatives for the food industry: Recent developments, challenges and prospects. Trends Food Sci. Technol. 2008, 19, 644-656. [CrossRef]

47. Singh, J.; Kaur, L.; McCarthy, O.J. Factors influencing the physico-chemical, morphological, thermal and rheological properties of some chemically modified starches for food applications-A review. Food Hydrocoll. 2007, 21, 1-22. [CrossRef]

48. Carvajal-Millan, E.; Landillon, V.; Morel, M.H.; Rouau, X.; Doublier, J.L.; Micard, V. Arabinoxylan gels: Impact of the feruloylation degree on their structure and properties. Biomacromolecules 2005, 6, 309-317. [CrossRef] [PubMed]

(C) 2019 by the authors. Licensee MDPI, Basel, Switzerland. This article is an open access article distributed under the terms and conditions of the Creative Commons Attribution (CC BY) license (http://creativecommons.org/licenses/by/4.0/). 